$\frac{\text { DE }}{\text { DE GRUYTER }}$ OPEN

\title{
THE OUTCOMES OF THE ROMANIAN EDUCATIONAL SYSTEM AND ECONOMIC INDICATORS
}

\author{
Alexandru JIVAN \\ West University of Timisoara, Romania \\ Ciprian Alexandru ȘIPOȘ ${ }^{*}$ \\ West University of Timisoara, Romania \\ Janeta WEISZ \\ Christian University "Dimitrie Cantemir"
}

\begin{abstract}
The paper highlights some important correlations between the outcomes of the Romanian educational system and certain key indicators concerning the Romanian economy. The indicators are selected on the basis of the logic correlations and considering the limits of available data. The time-lag models were used because the macroeconomic effects of the factorial indicators considered as determinants on dependent variables cannot be usually detected in the same year. The results allowed interesting discussions concerning the Romanian education system and its fundingrelated evolutions in the last decade.
\end{abstract}

JEL classification: I21, I28, 015

Keywords: outcomes of education, material and human efforts for education, macroeconomic effects

\section{Introduction}

Education and its correlations with the economic indicators can always reveal interesting aspects, on diverse time horizons. The paper proposes an analysis of the correlations between outcomes of education and some economic indicators, concerning, on the one hand, the economic effort for carrying out the educational process, and, on the other hand, the state of economy as a whole. The research is made inside the frame of the topic concerning the productivity of education,

${ }^{*}$ Corresponding authors. Address: West University of Timisoara, Faculty of Economics and Business Administration, J.H. Pestalozzi, no. 16,300115, Timisoara, 0040.744.834.835, Email: ciprian.sipos@e-uvt.ro 
dedicated to the case of Romania. The main purpose of the paper is to reveal possible connections that can be relevant in a widened horizon concerning the productivity of education linked to the key economic indicators (see Jivan, 2014).

Usually the productivity of education is analysed in a business approach at the level of educational units, with stress on the didactic curricula, methods, management of the specialized institutions etc. Previous studies (Denison and Chung, 1976, Damme, 2004, Tavenas, 2004, Li and Prescott, 2009, Lehmann and Koelling, 2010, and Jivan et al., 2016) focus on such topics. The paper of Jimenez (2006) is also most important, for the focus on the education topic and for the presentation of the background analysis. Further, we highlight the important work of Djellal and Gallouj (2008), because they see productivity in educational services on the bases of a widened horizon. See also Jivan (2014) and Jivan et al. (2016), for some short references to the important work of Djellal and Gallouj (2008).

In the view of our research, productivity is differently approached, in a not common conception, as the global productivity of the national educational system. Namely, indicators concerning the outcomes of education as high school graduation rate and number of graduates were used, in correlation with some key economic indicators (GNP, GNP/capita, GDP, GDP/capita, GDP/person employed).

The study presented is made on certain groups of factors established according to the criteria described in the paper by using diverse directions of the presumed causal influences. The data sets were selected from the available data, in the purpose of allowing certain time lags of the correlations, as shown in the second section. The econometric analysis was made following Jula (2003 and 2011) and Şipoş and Preda (2006).

Certain specific correlations between the outcomes of education and certain economic indicators in Romania are revealed, as detailed by the three main hypotheses developed in the second section. The econometric analysis of the hypotheses is made in the fourth section, taking into account a period of time that include the economic crisis after 2007. The empirical research is significant from the point of view of the widened approach on the analysed correlations that comes from our different conception about global productivity, based on the mediated and long term effects of education on the economy (see also Jivan, 2014). The econometric results confirm the hypotheses formulated, as shown in the fourth section, emphasizing the maximal relevance of the correlations for a maximum time lag of 2-4 years. They allow interesting interpretations concerning the Romanian education system and its funding-related evolutions in the last decade.

\section{The conceptual model. Methodology issues}

The conceptual model regarding the influences of the education system at the macroeconomic level presented in Table 1 consists in the system of correlations considering the research hypotheses $\mathrm{H} 1$ and $\mathrm{H} 2$. The datasets were properly used to manifest the causal elements of complex indicators of educational outcomes in the relationship with the economy. Thus, the indicators have been chosen considering the professional results of education either as an influence factor or, respectively, as an effect of the selected economic indicators. The selection of indicators was done limited to the available data, using databases from the World Bank and National Institute of Statistics of Romania. 
The analysis is made at global level, not at the individual entity level, as economic enterprise or educational institution, nor at the level of individuals as teachers, pupils, students. This conceptual choice can be considered both as added value and limit of the research, assumed from the beginning of conception of the work.

Based on these considerents, the conceptual model regarding the relationships between educational system in Romania and some key economic indicators is presented in the Table 1:

Table 1. The conceptual model regarding the influence of the education system at the macroeconomic level

\begin{tabular}{|c|c|c|}
\hline Hypotheses & & Results presumed \\
\hline H1: $I_{\text {prof }} \rightarrow I_{e c}$ & \multirow{3}{*}{$\begin{array}{l}\text { Educational } \\
\text { Services } \\
\text { Productivity }\end{array}$} & $\begin{array}{l}\text { The professional outcomes of the education } \\
\text { system }\left(I_{\text {prof }}\right) \text { have an important influence on } \\
\text { general economic indicators }\left(l_{e c}\right) \text {, proving to } \\
\text { be responsible for many problems in the real } \\
\text { economy and social life. }\end{array}$ \\
\hline H2: $I_{e c} \rightarrow I_{\text {prof }}$ & & $\begin{array}{l}\text { On the other hand, the general economic } \\
\text { situation of the country }\left(l_{e c}\right) \text {, has an important } \\
\text { effect on the evolution of the indicators } \\
\text { describing the professional outcomes of the } \\
\text { education system }\left(I_{\text {prof }}\right) \text {. }\end{array}$ \\
\hline H3: lefort $\rightarrow$ Iprof & & $\begin{array}{l}\text { Indicators of human and material efforts for } \\
\left.\text { education ( } I_{\text {efort }}\right) \text { are influencing the strictly } \\
\text { professional outcomes of education }\left(I_{\text {prof }}\right)\end{array}$ \\
\hline
\end{tabular}

Constrained by the availability of the indicators and the way they - and correlations that might exist between them - may be logically suitable to the goals of our research, the analysis has resulted in the structure below (Weisz, Jivan, 2014, Jivan et al., 2016):

- Strictly professional outcomes in education ( $\left.I_{\text {prof }}\right)$ is the group of indicators for which we were able to choose, within the limits of available data on sufficient long periods: total number of graduates, the number of researchers in R\&D and the high school graduation rate. Thus, among this group there are some direct outcome indicators (total number of graduates and high school graduation rate) and are also included the long-term outcome indicator capturing the level of professionalism at national level (number of researchers working in R\&D).

- Indicators of material and human effort for education (l $\left.l_{\text {efort }}\right)$ include public expenses assumed to ensure the educational system: (number of) schools, school laboratories, classrooms and school offices, teaching staff (number), gross average earning per employee in education (the recent meaning of expenditure for staff working in education).

- Economic Indicators ( $\left.l_{e c}\right)$ include the key indicators of the Romanian economy: Gross Domestic Product (GDP), Gross National Product GNP), GDP/capita, GNP/capita, GDP/employed person). 
The length of datasets is limited by the availability of statistical data. We have chosen only the indicators for which we can verify correlations for sufficiently extended periods, to ensure relevance and to allow a rigorous study. The selection was also limited by the need for time lag calculations because in the education system the effects are not expected in the same year, they appearing ussualy over minimum three or four years, given by the length of a school cycle. In our calculations, we went to a lag of up to six years.

Of course, there are other indicators, involved in logical correlations: the causal mechanisms are more complex, but actual choice of indicators used for this analysis was done as shown above. In a few cases, we have allowed to complete data series (where figures were missing for a year, or even two, joined or dispersed) by approximate extrapolations, based on average data, particularly weighted, with the amounts years adjacent to the missing. Also, we consider that very few approximations did not affect significantly, perhaps not noticeable, overall correlations to those sets of data.

We mention that, as can be seen in detailing above, the groups considered can sometimes contain repetition or duplication of influences, especially in the case of economic indicators; for example, we included in the same group indicators: GDP/capita and GNP/capita.

Such double determination may influence the analysis in research aimed to establish the quantitative values to variables and parameters of empirical analysis. Our study is, however, focused on the principles of influences concerning educational productivity and not on the exact magnitude of these influences; therefore, in our opinion, the repetition does not affect the conceptual and qualitative principles.

The econometric analysis is based on different time lags of the indicators: namely with the gap of one year in some cases going up to a time lag of six years. We noted that some possible influences are logically rather more than two or three years, others more than five years, or other possible variants.

\section{Overview of key data as the base of research. Evolutions in the analysed period}

The first hypothesis, which means the correlation between strictly professional outcomes in education ( $\left.I_{\text {prof }}\right)$ as influence factor and economic indicators $\left(l_{e c}\right)$ as dependent variable, is based on the facts that in the period 2000-2012 the high school graduation rate and the total number of graduates, have developed oscillations that might be considered minor until around 2008-2009. Thus, the longterm trend was relatively constant in the analysed period. Also the number of researchers in $R \& D$ has remained relatively constant; its decline, although slightly, is noticed since 2006, being more pronounced since 2010.

The decrease in the number of graduates began in 2007, and from 2008 the decline is very visible for the entire Romanian educational system; the high school graduation rate is decreasing, the year 2011 registering very low levels.

Thus, there is a downward trend for all these indicators, although there were taken some beneficial measures to the education system, such as computerized distribution of teachers participating in the tenure competition, the increased investment from structural funds, which should have positive effects on the graduation indicators. It explains the fact that the high school graduation rate has increased from 2011 to 2012 , which is however too little. 
Among the possible explanations, certain legislative changes may be mentioned, that were imposed without sufficient justification, in our opinion, including how it has developed and introduced the National Education Law no. 1/2011 without a proper preliminary debate. It is important to remember in these circumstances, the basis on that were applied certain measures, namely the global economic crisis and its overall impact. Thus, a number of important factors have intervened in the context, including the decreasing of the expenses related to education and, and above all, the reducing of salaries for teachers, as can be seen on the second hypothesis examined in this paper.

In order to analyse the relationship between outcomes of education and the economic context, we present the key economic indicators used. Thus, the indicator Public spending on education registered a relatively constant variation (between 3-4\%) while the GNP registered a significant increasing trend of $173 \%$ in the period 2000-2012. They can be considered as having a contribution to the changes in the Romanian educational system in the considered period (as influence factors) but also are influenced by educational outcomes, as determined variables. We mention that GNP per capita and GDP per person employed were also considered in our analysis.

As we have presented above, the Indicators of material and human effort for education (l $l_{\text {efort }}$ include public expenses assumed to ensure the functioning of the educational system. Here, two main aspects are highlighted: firstly, most of the indicators for education effort (number of school laboratories, workshops and schools, classrooms and school classrooms, nominal average monthly gross earning in education) recorded a relatively constant evolution without significant changes; only in the case of average monthly gross earning in education there was a slight change in 20042005, which is the period since the passing of the old currency (LEU) to the new parity of the national currency (RON). Secondly, the teaching staff has significantly decreased between 2000 and 2012, from 294.938 persons to 245.174 persons, which is one of the factors that contributed to the decline in graduation rates, as direct outcomes of educational system.

\section{The empirical analysis}

In our study we used the linear regression model with time-lags; estimators determined by least squares method correspond to the objective pursued if the expected value of each estimator is equal to the actual value of the parameter and the variance of each estimator is as low as possible in relation to the number of samples.

One methodological approach concerns that the order of magnitude of data and units are very different from one indicator to another, even in the same logical category; namely, there are variables expressed in different monetary units (RON, EUR) or physical units (number of people, number of schools, physical units related material endowment, and so on). As a result, to analyse the correlation between the influence factors and dependent variables, the standardization of data was necessary (see Table 2); that is the reason for that we conducted the analysis based on standardized (normalized) data. 
Table 2. Standardized data of $I_{\text {prof }}$, lefort and $l_{e c}$

\begin{tabular}{|l|l|l|l|}
\hline Years & $\boldsymbol{I}_{\text {prof }}$ & $\boldsymbol{l}_{\text {efort }}$ & $\boldsymbol{l}_{\mathbf{e c}}$ \\
\hline 2000 & 0.19348 & 0.54328 & -1.26374 \\
\hline 2001 & 0.03186 & 0.81019 & -1.14616 \\
\hline 2002 & 0.41324 & 0.75875 & -0.97487 \\
\hline 2003 & 0.27326 & 0.61432 & -0.81257 \\
\hline 2004 & 0.74810 & 0.58826 & -0.58061 \\
\hline 2005 & 1.03874 & -0.10078 & -0.34593 \\
\hline 2006 & -0.05390 & -0.22639 & 0.40616 \\
\hline 2007 & 0.54037 & -0.26180 & 0.44068 \\
\hline 2008 & 0.34156 & -0.11771 & 1.36697 \\
\hline 2009 & 0.20526 & -0.31434 & 0.63586 \\
\hline 2010 & -0.10802 & -0.63157 & 0.69324 \\
\hline 2011 & -2.16468 & -0.86283 & 0.77036 \\
\hline 2012 & -1.45932 & -0.79941 & 0.81060 \\
\hline
\end{tabular}

Correlation analysis for variables is performed using Pearson correlation coefficient, the R Square and the partial correlation coefficients and determination. We also used the linear regression model for lagged variables, and Fisher and Student tests for empirical analysis. Starting with the first hypothesis $(H 1)$ which assumes that the professional outcomes of the education system (Iprof) have an important influence on general economic indicators $\left(l_{\text {ecc }}\right.$ ), the econometric analysis did not reveal very strong correlations, but highlighted that exists both positive and negative influences.

The positive influences are low or moderate for diverse time-lags. The moderate positive correlations and the main results of linear regression are shown in the Table 3 and the Charts 1, 2, 3 and 4.

Table 3.The positive correlations between $l_{e c}$ and $l_{\text {prof }}$

\begin{tabular}{|l|l|r|r|r|r|r|}
\hline No. & $\begin{array}{c}\text { Variable of } \\
\text { influence }\end{array}$ & $\begin{array}{c}\text { Pearson } \\
\text { correlation }\end{array}$ & $\begin{array}{c}\mathbf{R} \\
\text { Square }\end{array}$ & $\begin{array}{c}\mathbf{t} \text { stat } \\
\text { for } \boldsymbol{\beta}\end{array}$ & $\mathbf{F}$ & $\boldsymbol{\beta}$ \\
\hline 1. & Iprof (lag of 3 years) & 0.640 & 0.410 & 2.97 & 6.264 & 0.972 \\
\hline 2. & $I_{\text {prof (lag of 4 years) }}$ & 0.746 & 0.557 & 3.17 & 10.068 & 1.072 \\
\hline 3. & $I_{\text {prof (lag of 5 years) }}$ & 0.664 & 0.441 & 2.35 & 5.524 & 0.944 \\
\hline 4. & $I_{\text {prof (lag of 6 years) }}$ & 0.726 & 0.528 & 2.59 & 6.715 & 1.093 \\
\hline
\end{tabular}




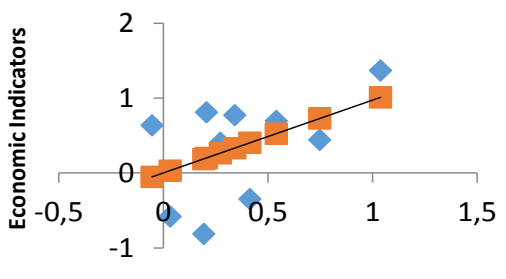

Professional results of education

Fig. 1. Moderate positive correlations at a lag of 3 years

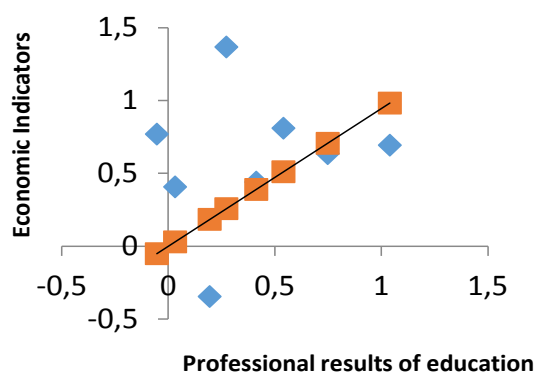

Fig. 3. Moderate positive correlations at a lag of 5 years

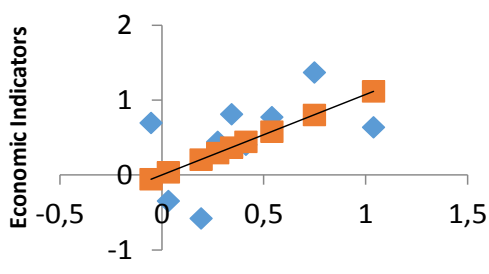

Professional results of education

Fig. 2. Moderate positive correlations at a lag of 4 years

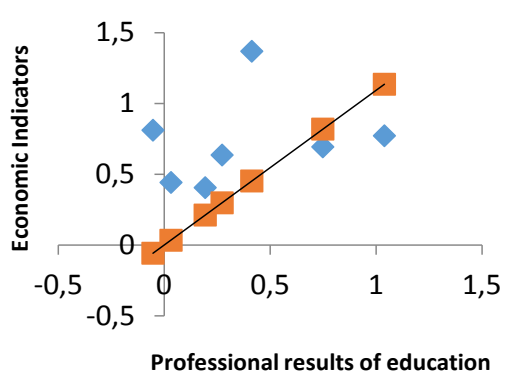

Fig. 4. Moderate positive correlations at a lag of 6 years

We can observe that, for a time lag of 3-6 years, the correlations between factorial variable $I_{\text {prof }}$ and the dependent variable $l_{e c}$ are moderate positive.

The most significant correlation is related to a time lag of four years, which corresponds logically to the duration after which $I_{\text {prof }}$ can be found in the economy, and can be explained by the average duration of a study cycle.

Further, we synthetically present the correlations regarding the influence of $l_{e c}$ on $I_{\text {prof, }}$ according to second research hypothesis $(H 2)$, which assumes that the general economic situation of the country $\left(l_{\text {ec }}\right)$ has an important effect on the indicators describing the professional outcomes of the education system (I $\left.I_{\text {prof }}\right)$. In this case, the correlations are negative, and the relevant ones are presented in the Table 4 , and Charts 5 and 6$)$ :

Table 4. The moderate negative correlations concerning / prof

\begin{tabular}{|l|l|r|r|r|r|c|}
\hline No. & $\begin{array}{c}\text { Variable of } \\
\text { influence }\end{array}$ & $\begin{array}{c}\text { Pearson } \\
\text { correlation }\end{array}$ & $\begin{array}{c}\mathbf{R} \\
\text { Square }\end{array}$ & $\begin{array}{c}\mathbf{t} \text { stat } \\
\text { for } \boldsymbol{\beta}\end{array}$ & $\mathbf{F}$ & $\boldsymbol{\beta}$ \\
\hline 1. & $l_{e c}$ (lag of 3 years) & $-0,780$ & 0,608 & 3,74 & 13,999 & $-0,848$ \\
\hline 2. & $l_{e c}$ (lag of 4 years) & $-0,721$ & 0,520 & 2,94 & 8,687 & $-0,802$ \\
\hline
\end{tabular}




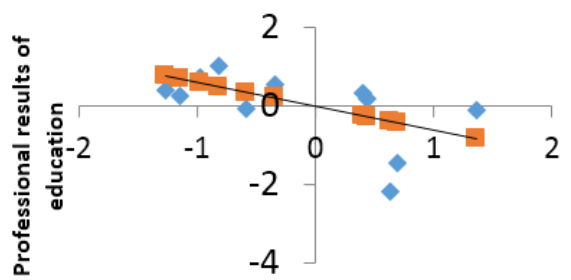

Economic Indicators

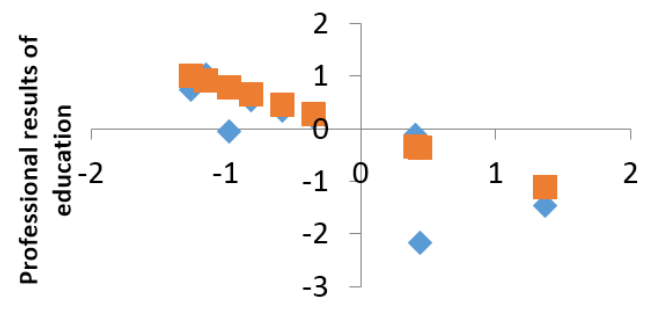

Economic Indicators

Fig. 6. Moderate negative correlations at a lag of 4 years
Fig. 5. Moderate negative correlations at a lag of 3 years

From analysis on the correlation between factorial variable $l_{e c}$ and dependent variable $I_{\text {prof, }}$ it follows that, for a time lag for 3 and 4 years, they are negative, but moderate. The Pearson correlation coefficient indicates a moderate negative relation between the variables studied, and the coefficient of determination ( $R$ Square) shows that over $60 \%$, respectively $52 \%$, of the variation of $I_{\text {prof }}$ can be explained by the influence of $l_{e c}$ for a time lag of 3 and 4 years.

Further, the Fisher test confirms that coefficient $\beta$ is negative, and the relationship between $l_{\text {ec }}$ as factorial variable and $l_{\text {prof }}$ as result variable is inverse: when $l_{\text {ec }}$ increases, $I_{\text {prof }}$ take a downward trend, and vice versa. For the case of a time lag of 2 and, respectively, 5 years, econometric correlations between the dependent variable $I_{\text {prof }}$ and variable factor $l_{e c}$, are weak and still negative (see Table 5, and Charts 7 and 8 ).

Table 5. The weak negative correlations concerning $I_{\text {prof }}$

\begin{tabular}{|l|c|r|r|r|c|c|}
\hline No. & $\begin{array}{c}\text { Variable of } \\
\text { influence }\end{array}$ & $\begin{array}{c}\text { Pearson } \\
\text { correlation }\end{array}$ & $\begin{array}{c}\mathbf{R} \\
\text { Square }\end{array}$ & $\begin{array}{c}\mathbf{t} \text { stat } \\
\text { for } \boldsymbol{\beta}\end{array}$ & $\mathbf{F}$ & $\boldsymbol{\beta}$ \\
\hline 1. & $l_{e c}$ (lag of 2 years) & $-0,565$ & 0,319 & 2,16 & 4,705 & $-0,602$ \\
\hline 2. & $l_{e c}$ (lag of 5 years) & $-0,547$ & 0,300 & 1,73 & 3,001 & $-0,685$ \\
\hline
\end{tabular}

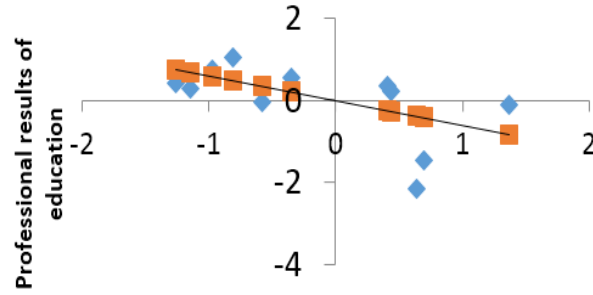

Economic Indicators

Fig. 7. Weak negative correlations at a lag of 2 years

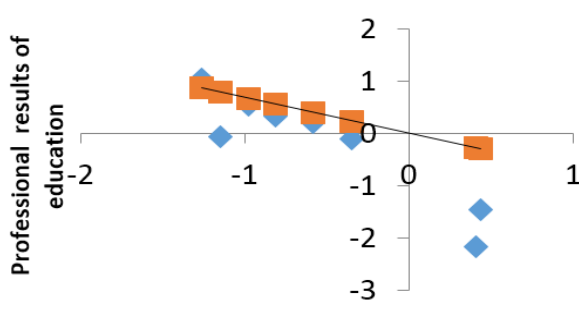

Economic indicators

Fig. 8. Weak negative correlations at a lag of 5 years 
Also in the case of the second hypothesis, considering $I_{\text {prof }}$ as dependent variable and lefort as influence factor, we found one positive econometric correlation and moderate, i.e., for the time-lag corresponding to one year. The gap is logical from the point of view of causality: a change in spending for education is succeeded by an improving of $I_{\text {prof }}$ after approximately a year (at least one year).

The Pearson correlation coefficient shows that the influence of $I_{\text {efort }}$ on $I_{\text {prof }}$ is moderate, meaning that the facilities and the material and human effort from a year determines an increased high school graduation rate in the next year, even if the coefficient of determination indicates that the intensity of relationship between the variables is only moderate.

After the correlation corresponding to one year time-lag between the data sets, the following intensity of correlation is for two years time-lag; for longer intervals, the relationship remains positive, although it is lower intensity (see Table 6):

Table 6. The positive weak correlations concerning $I_{\text {prof }}$

\begin{tabular}{|l|c|r|r|r|r|r|}
\hline No. & $\begin{array}{c}\text { Variable of } \\
\text { influence }\end{array}$ & $\begin{array}{c}\text { Pearson } \\
\text { correlation }\end{array}$ & $\begin{array}{c}\text { R } \\
\text { Square }\end{array}$ & $\begin{array}{c}\text { t stat } \\
\text { for } \boldsymbol{\beta}\end{array}$ & $\mathbf{F}$ & $\boldsymbol{\beta}$ \\
\hline 1. & $l_{\text {efort }}(2$ years) & 0,592 & 0,350 & 2,32 & 5,402 & 1,054 \\
\hline 2. & $l_{\text {efort }}(3$ years $)$ & 0,525 & 0,276 & 1,85 & 3,432 & 0,998 \\
\hline 3. & lefort $(4$ years) & 0,537 & 0,288 & 1,80 & 3,243 & 1,036 \\
\hline
\end{tabular}

The last hypothesis tested $(H 3)$ assumes that Indicators of human and material efforts for education (l $l_{\text {efort }}$ ) are influencing the strictly professional outcomes of education ( $\left.I_{\text {prof }}\right)$. Thus, the number of schools and labs as material effort indicators and, respectively, the number of teachers as a human effort indicator has a significant correlation with the high school graduation rate and the number of graduates during 2000-2012. A strong direct influence can be considered in the short-term (time-lag of one year), but the influence is weaker as the considered time-lag increases.

On this hypothesis, regarding the influencing on I prof by facilities provided to education (and, generally, by lefort), it appears that the number of units and school laboratories as indicators of material effort and teaching staff as an indicator of human effort, present a significant correlation with high school graduation rate and the number of graduates during 2000-2012. It can be considered a strong influence in the direct sense, on short-term (time-lag of one year); for example in 2001 against 2000 , teaching staff percents grew from $29.5 \%$ to $30.01 \%$, which influenced the increased graduation rate from $86.3 \%$ in 2001 to $86.7 \%$ in 2002; but the intensity of this positive influence is increasingly irrelevant as the considered time-lags grows, as demonstrated by econometric research (see Charts $9,10,11$, and 12):

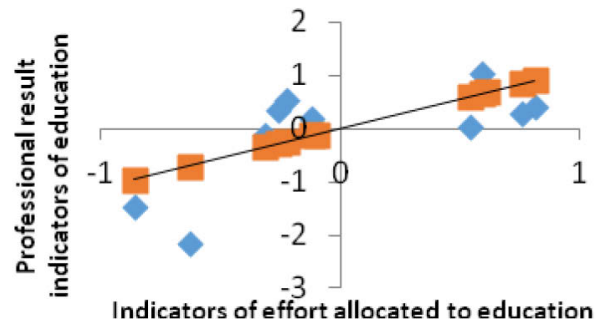

Fig. 9. Moderate positive correlations at a lag of 1 year

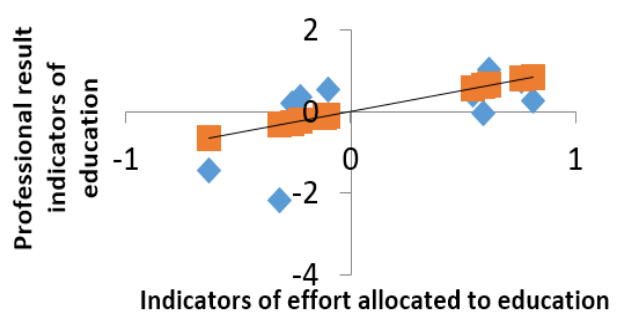

Fig. 10. Moderate positive correlations at a lag of 2 years 


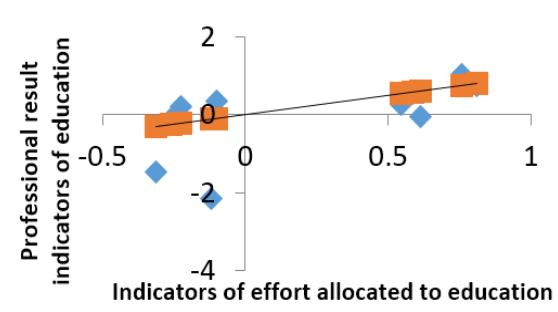

Fig. 11. Weak positive correlations at a lag of 3 years

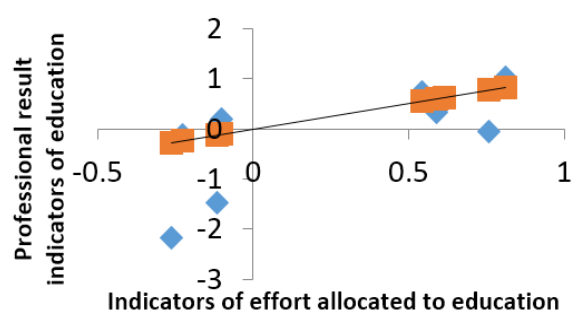

Fig. 12. Weak positive correlations at a lag of 4 years

In our research we have not tested also the reverse version of this hypothesis (a possible hypothesis $\mathrm{H} 4$ ), because we consider that the influence which I prof can have on lefort makes no sense; it might be speculated that if the peoples are trained in a higher education quality and the professional education system outcomes are better, the more likely there will be taken more adequate decisions. These better decisions can result in the amplification of the societies' efforts to ensuring the nation's future through education, as there are many examples of nations that have lack of other resources, but relying on education, and has a great development.

Such influences may occur only after long intervals of time in which the present graduates will be the next nation's decision makers, so on very long term. But the large number of factors involved, especially for the medium developed economies, like in the case of Romania, makes such correlations to be not really significant; moreover, on long-term (in our case a time-lag of maximum 6 years), possible econometric correlations show a very low intensity.

Making a succinct centralizing of the results of correlations for lagged variables, we have considered relevant to highlight (in Table 7) the strongest relationships and, respectively, the weakest ones, as can be seen below:

Table 7. Centralizing the results of correlations for lagged variables

\begin{tabular}{|c|c|c|c|}
\hline $\begin{array}{c}\text { Moderate } \\
\text { correlations } \\
\text { (positive) }\end{array}$ & $\begin{array}{c}\text { Weak } \\
\text { correlations } \\
\text { (positive) }\end{array}$ & $\begin{array}{c}\text { Moderate } \\
\text { correlations } \\
\text { (negative) }\end{array}$ & $\begin{array}{c}\text { Weak correlations } \\
\text { (negative) }\end{array}$ \\
\hline $\begin{array}{l}I_{\text {prof }} \rightarrow I_{e c} \\
\text { (lags of 3-6 years) }\end{array}$ & $\begin{array}{l}l_{\text {efort }} \rightarrow I_{\text {prof }} \\
\text { (lags of } 2-4\end{array}$ & $\begin{array}{l}l_{\text {ec }} \rightarrow I_{\text {prof }} \\
\text { (lags of } 3 \text { and } 4\end{array}$ & $\begin{array}{l}l_{\text {ec }} \rightarrow I_{\text {prof }} \\
\text { (lags of } 2 \text { years }\end{array}$ \\
\hline $\begin{array}{l}l_{\text {efort }} \rightarrow I_{\text {prof }} \\
\text { (lag of } 1 \text { year) }\end{array}$ & years) & years) & and 5 years) \\
\hline
\end{tabular}

\section{Conclusions}

The research was designed based on the literature review and the analysis of empirical data, according to their availability and other limitations, regarding the correlation between main outcomes of the Romanian educational system and certain 
key indicators concerning the Romanian economy. The correlations were analysed on a period of 13 years with various time-lags by using usual econometric methods as Pearson correlation coefficient, linear regression model for lagged variables, the Fisher test and the Student test for significance of regression coefficients.

The results let us to conclude the existence of interesting correlative determinations between the groups of indicators studied, on the periods and timelags considered, which logically correspond to the educational cycles, as shown above in the paper.

Given those conceptual premises, we made the first hypothesis assuming that the key economic indicators considered as a dependent variable are significantly influenced by professional outcomes of educational system. That hypothesis was econometrically confirmed in a moderate level in the case of Romania. The length of dataset used allowed a pertinent analysis to a maximum time-lag of 6 years (correlations were positive), with diverse intensity of effects, depending on the quality of education, expressed by total number of graduates, the number of researchers in R\&D and the high school graduation rate.

In some cases, the invalidation by the empirical analysis of relationships presumed for certain temporal dimensions forced us to revise the number of years for which we considered the time-lag between the influence factors and dependent variables. Therefore, the resulted significant time lags was for one year up to 6 years. Over six years, the correlations are not showing relevant econometric results to justify further analysis.

The second hypothesis, takes into account the economic indicators, considered as an independent variable, influencing the professional outcomes of educational system. Paradoxically, the calculations do not validate that assumption, showing negative correlations (against the relation that can be presumed in the normal logic). Seeing these results, we restricted the research period: compared to 19902012, as initially tried, we remade the calculations for the period 2000-2012 only. But there were no better results.

We can think that, regardless of economic evolutions, Romanian governments practically have given to education about the same interest that would be granted in the case of inverse general developments in the economy. Although Romania's overall trend of development over the analyzed period was positive, most of the educational system's output indicators have fallen. We can say that this reality is validated by the personal experience of most Romanians who had students or pupils in their family.

The last hypothesis analysed, reflects the influence of indicators of material and human effort for education on professional outcomes of educational system. In this case, the research confirmed that the results obtained in education are influenced by the human and material effort for education. The correlations are positive, which shows that an increase in the number of schools, labs, number of teachers, and theachers' wages, have a positive influence on the graduates from high school and graduation rate, with direct positive impact on the labour market.

The strongest correlation is for a time-lag of one year; increasing the timelag resulted in weaker correlations, meaning that ensuring these conditions for the teaching process (the young people have a place where to learn and enjoy good schools, and the educational staff is encouraged by wages), is reflected in the results of graduates only on short-term. 
The main ideas that we have drawn during research can be considered as representing a small contribution to the study of education, but relevant: the empirical research presented is significant at least in terms of broad-comprehensive optics on correlations considered, which lies in a complex vision productivity; as developed in (Jivan, 2014), namely, the specific manner of serving the economy, opening to mediated and long-term effects. They can be correlated with other studies of the authors, as (Jivan et al., 2016).

The question of quantitative measurement of productivity in education remains open, and also, in particular, the problem of quantifying the qualitative aspects (estimating specific immaterial issues) which was not addressed in this research. Some guidelines to follow for future research can also aim to extend both the geographical analysed area (in the educational system of other countries too, possibly from Eastern Europe), and the temporal area investigated, and to improve research concerning the opportunities of productivity growth in education.

\section{Acknowledgment}

This work was supported by the project "Excellence academic routes in doctoral and postdoctoral research - READ" co-funded from the European Social Fund through the Development of Human Resources Operational Programme 2007-2013, POSDRU/159/1.5/S/137926.

\section{References}

*** National Institute of Statistics, Tempo - online statistical data, http://statistici.insse.ro/shop/?lang=ro, accessed at 10.11.2015

*** World Bank Group, Data Bank by Country, retrieved from http://data.worldbank.org/country/romania, accessed at 10.11.2015

Damme D.V. (2004) Standards and Indicators in Institutional and Programme Acreditation in Higher Education, A Conceptual Framework and a Proposal, in Vlăsceanu L., Barrows, L. C., Indicators for Institutional and Programme Accreditation in Higher/Tertiary Education, Studies on Higher Education Series, Bucharest: UNESCO-CEPES, pp.127-159.

Denison F. E., Chung R. W. (1976) How Japan's Economy Grew so Fast, Washington DC Brookings Institution.

Djellal F., Gallouj, F. (2008) Measuring and improving productivity in services, Edward Elgar Publishing, Cheltenham, Northampton.

Jimenez A. C. (2006), Modelo de capital intelectual de la Consejería de Educación de la Junta de Andalucía. Indicadores de capital humano y gestión del conocimiento, Universidad de Málaga. Departamento de Economia y Administracion de Empresas, Octubre.

Jivan, A. (2014) Productivité et servicité, Economies et Sociétés, No. 4/2014, Cahiers de I'ISMEA, No 4/2014 (Série « Economie et Gestion des Services » EGS No 15, Avril), pp 579-599.

Jivan, A. et al. (2016), Elemente de productivitate a serviciilor intelectuale, Mirton Publishing. Timisoara

Jula, D. (2003) Introducere în Econometrie. Professional Consulting Publishing. Bucharest. 
Jula, D. (2011) Econometrie. Retrieved from:

http://www.postdoc.acad.ro/data/files/ECONOMETRIE_-_prof.Jula.pdf, accessed at 12.09.2016.

Lehmann C., Koelling M. (2010) The Productivity of Services: A systematic literature review, pp. 12-18, http://www.reser.net/materiali/priloge/slo/kolling_m.pdf, accessed at: 18.10.2016.

Li X., Prescott D. (2009) Measuring productivity in the service sector, University of Guelph, March, online at http://cthrc.ca/en/resource_centre/ /media/Files/CTHRC/ Home/research_publications/productivity/Measuring_Productivity_Service_Sector Sept_EN.ashx, accessed at 23.05.2016.

SSipoş C., Preda C. (2006) Econometrie, Mirton Publishing, Timisoara

Tavenas, F. (2004)Quality Assurance: A Reference System for Indicators and Evaluation Procedures, European University Association, online at http://www.eua.be/ eua/jsp/en/upload/elu_en.1082042243703.pdf, accessed at 10.07.2016.

Weisz J., Jivan A. (2014) Study on productivity indicators in education. SEA -Practical Application of Science, Volume I, Issue 2 (4) /2014, pp. 683-688. 